\title{
Estrategias alimentarias y de subsistencia prehispánica en el Centro-Oeste de Mendoza: Consumo y descarte en el sitio arqueológico Agua Amarga
}

RMA

Arqueología

\author{
María José Ots*, Nurit Oliszewski** y Jorge García Llorca*
}

*Unidad de Antropología, Instituto de Ciencias Humanas, Sociales y Ambientales. CONICET, Facultad de Filosofía y Letras, Universidad Nacional de Cuyo. E-mail: mjots@mendoza-conicet.gob.ar - gllorca@mendoza-conicet.gob.ar **Instituto Superior de Estudios Sociales, CONICET, Facultad de Ciencias Naturales e Instituto Miguel Lillo, Universidad Nacional de Tucumán.

E-mail: nuritoli@yahoo.com.ar

\begin{abstract}
Resumen
Se presenta el análisis de un depósito de desechos asociados a la alimentación en Agua Amarga (departamento de Tupungato, en el Centro Oeste de la provincia de Mendoza). Agua Amarga es un sitio residencial de actividades múltiples ubicado en el piedemonte del Valle de Uco, a $1000 \mathrm{msnm}$. Los fechados obtenidos sobre cerámica y restos vegetales del contexto lo ubican en el período tardío y de dominación incaica regional.

El propósito del trabajo es estudiar estrategias de procesamiento, consumo y descarte de alimentos que asimismo contribuyan a la discusión sobre las estrategias de subsistencia prehispánicas en el Norte y Centro de Mendoza. Se aplican métodos y técnicas específicos para la identificación y el análisis de los restos, y se proponen hipótesis alternativas sobre dicho contexto. Los materiales recuperados, la mayoría de ellos termoalterados y muy fragmentados, incluyen macrorrestos arqueobotánicos (principalmente Zea mays y Phaseulus vulgaris), restos óseos (algunos elementos identificados como Lama sp.), fragmentos de distintos recipientes cerámicos y de artefactos de molienda. Finalmente, se discuten prácticas asociadas con la alimentación y la subsistencia, con especial referencia a la producción y consumo de maíz en el área.
\end{abstract}

Palabras clave: alimentación; subsistencia; maíz; Mendoza.

Food and subsistence strategies in the prehispanic Mendoza Midwest: Consumption and discard at the site Agua Amarga

\begin{abstract}
We present the study of a refuse deposit associated with feeding activities in the archaeological site Agua Amarga (Tupungato department, Middle West of Mendoza province). This is a residencial site of multiple activities located in the foothill in Valle de Uco, to 1000 masl. We dated ceramics and vegetal remains that locate the context in the late period and during regional inca domination.

Our goal is to study strategies of processing, consumption and discarding of foods that also contribute in the discussion on the prehispanic strategies of subsistence in the North and Center of Mendoza province.

In this paper we applied specific methods and techniques for the identification and the analysis of the remains, and we propose alternative hypotheses on this context. Materials recovered, majority of them burnt and very fragmented, include macro archaebotanical remains (mainly Zea mays and Phaseulus vulgaris), bone remains (some elements identified as Lama sp.), fragments of different ceramic containers and grinding stones. Finally, we discuss practices associated with food and subsistence, especially in terms of production and consumption of maize in the area.
\end{abstract}

Keywords: feeding; subsistence; maize; Mendoza.

La información etnohistórica ha sido durante décadas la principal fuente para el conocimiento de las estrategias de subsistencia en Cuyo durante el contacto hispanoindígena. La visión de comunidades productoras de alimentos desde el río San Juan al río Diamante que transmiten crónicas como la de Bibar (1966) se generalizó para toda el área (Michieli 1983, Prieto 2000). Estudios posteriores que incluyen documentos inéditos propusieron, para el Norte y Centro Oeste de Mendoza, la existencia de grupos diferenciados entre los huarpes, 
dedicados a actividades de subsistencia diversas y complementarias: unos a la recolección, complementada con la caza y la pesca, y otros a la agricultura y la ganadería (Parisii 1995).

El hallazgo de restos arqueobotánicos en sitios de la precordillera sostuvo para el Norte y Centro de Mendoza la producción agrícola basada fundamentalmente en el cultivo de maíz desde hace 2000/1500 años y la caracterización del área habitada por comunidades aldeanas cuya economía productora de alimentos le permitió sostener una alta demografía e, incluso, un excedente, asimilándolas a los grupos andinos del Noroeste argentino (Prieto 2000, Bárcena 2001, Lagiglia 2001).

Sin embargo, esta definición de las sociedades locales como "agropecuarias" a partir de los relatos posthispánicos o de criterios de presencia/ausencia de cultígenos ha sido discutida (Gil 1997-98), cuestionándose incluso la producción prehispánica de alimentos en Mendoza (Chiavazza y Mafferra 2007). El estudio de la subsistencia prehispánica en el área con objetivos y metodología específicos es reciente, y se ha realizado fundamentalmente a partir de datos arqueológicos y bioantropológicos (particularmente del análisis de isótopos estables) para discutir la intensidad de la estrategia productiva y la importancia de cultígenos como el maíz en la dieta de la población en la periferia del área andina, espacio de frontera con las sociedades de cazadores-recolectores (Novellino et al. 2004, Gil et al. 2006, 2009, entre otros).

Consideramos que el problema puede ser abordado integrando el estudio de la diversidad del registro arqueológico regional, en distintos momentos y diversos ambientes. El caso que presentamos corresponde al sitio Agua Amarga en el Valle de Uco, área ubicada en el Centro Oeste de la provincia de Mendoza (Figura 1). Las descripciones españolas tempranas consideran al Valle de Uco uno de los sectores más densamente poblados, habitado por huarpes que compartían las características que habían sido descritas para otros sectores de la provincia.

Por el momento, solo se han realizado estudios de isótopos estables y dieta que han incluido casos posthispánicos tardíos de las poblaciones del Valle de Uco (provenientes de cementerios indígenas de Cápiz, San Carlos y Viluco) (Novellino et al. 2003, Gil et. al 2009).

Agua Amarga es un sitio multicomponente de actividades múltiples, donde se han registrado ocupaciones desde el agroalfarero medio hasta el tardío bajo dominación incaica (siglos X-XV) (Ots 2007). El objetivo específico de este trabajo es estudiar estrategias alimentarias a partir del análisis de un contexto prehispánico tardío en el que identificamos restos macrobotánicos, óseos, líticos y cerámicos que asociamos al procesamiento, consumo y desecho de alimentos.

La investigación de contextos asociados con la alimentación en sitios residenciales del piedemonte no tiene antecedentes en la arqueología regional, por lo cual, nuestro propósito es contribuir, asimismo, a la discusión sobre la subsistencia de las poblaciones locales en Mendoza.

\section{Ubicación y antecedentes del sitio}

El área denominada Valle de Uco se encuentra en el Centro Oeste de la provincia de Mendoza, entre los ríos Mendoza y Diamante, y abarca dos ambientes: la cordillera al Oeste y el piedemonte al Este. El sitio Agua Amarga se encuentra en la finca homónima (distrito El Totoral, departamento de Tupungato), sobre el arroyo Agua Amarga, y entre la Ruta Provincial 89 y el Corredor Productivo (Ruta Provincial 52) (S33 $28^{\prime} 18.5^{\prime \prime}$ O69 11'29.3') (Figura 1). El sector, ubicado en el piedemonte entre los 1.200 y 1.000 msnm, es un glacis de acumulación cubierto por profundas capas de material aluvional, de pendiente aproximada entre $2^{\circ}$ y $10^{\circ}$. Las condiciones que caracterizan al área (altura, abundante caudal hídrico, suelos pedregosos y muy permeables sin problemas de drenaje o salinidad, amplitud térmica anual y diaria favorable) son óptimas para el desarrollo agrícola en la zona, tanto de productos de huerta como maíz, zapallo y poroto, como para la producción de frutales y uvas finas que constituyen la principal actividad económica en la actualidad (Gutiérrez de Manchón y Furlani de Civit 1997:233). Las características climáticas (temperatura, precipitaciones) ${ }^{1}$ se han mantenido, en términos generales, durante el Holoceno tardío (Zárate 2002). En el sitio se identificó la vegetación característica del sector de Bolsones y Huayquerías (Roig et al. s/f): Larrea divaricata, Larrea nítida, Geoffroea decorticants, Prosopis flexuosa, Ephedra triandra, Acantoliphia seriphioides, entre otros ${ }^{2}$.

Agua Amarga ha sido sometida a labores agrícolas desde la década de 1970, con el cultivo de parrales sobre la margen derecha del arroyo y frutales en la margen izquierda y en sectores bajos de la barranca del arroyo. Algunos trabajos previos han estudiado piezas cerámicas del sitio asignadas a contextos funerarios posthispánicos, recolectadas durante las primeras tareas de preparación del terreno agrícola (Lagiglia 1978, 1979; Prieto Olavarría 2005), sin embargo, los datos que presentamos corresponden a otro tipo de actividades que nos permiten sostener que éste sería, además, un sitio residencial con

\footnotetext{
1 Promedio anual histórico de temperatura de los últimos 10 años: $14,2^{\circ}(S=0,6)$. Datos de la Estación Meteorológica Agua Amarga (\$33³0'57,7”, 970 msnm). Dirección de Agricultura y Contingencias Climáticas. http://www.contingencias.mendoza.gov.ar/pronost.php

2 Relevamiento e identificación de las especies realizado por la Biól. Lic. Carmen Sartor.
} 


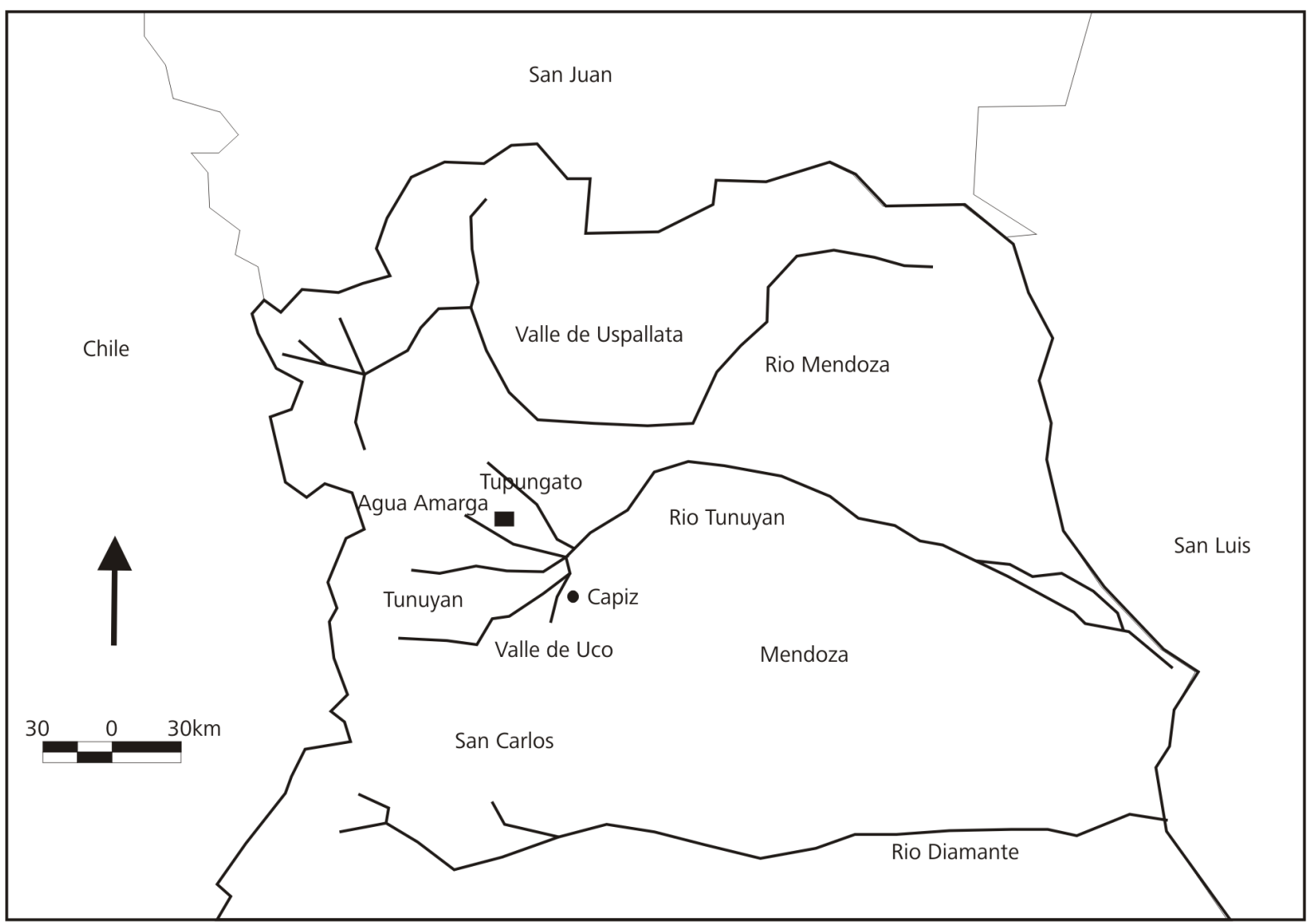

Figura 1. Norte y centro de la provincia de Mendoza. Ubicación relativa del sitio.

Figure 1. Upper and Cenral Mendoza Province. Relative location of the archaeological site.

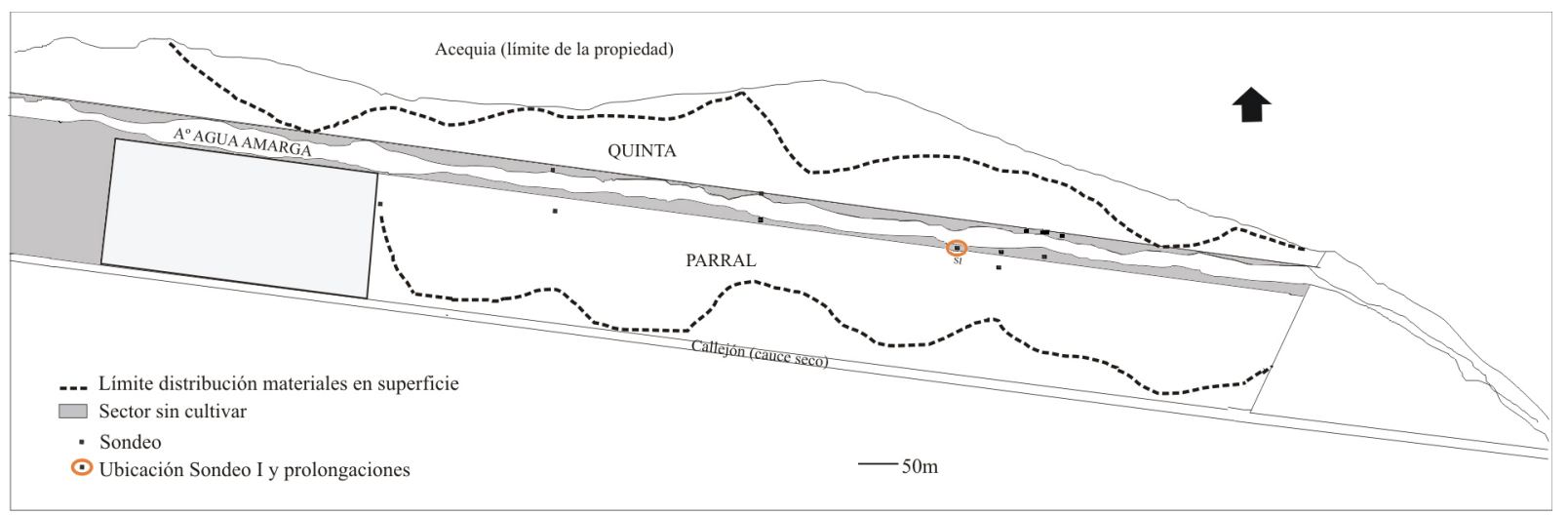

Figura 2. Agua Amarga: Límite de la distribución de materiales en la superficie del sitio y ubicación de los Sondeos I a XIII (Modificado del Plano de la Finca Agua Amarga. Dirección Provincial de Catastro. Mendoza, Julio de 1988).

Figure 2. Agua Amarga: surface archaeological materials limit and locatgion of Tes pits I to XIII (modified from Map of Finca Agua Amarga. Provincial de Catastro. Mendoza, July 1988).

otras funciones.

El parral y la quinta ocupan actualmente una superficie de $52 \mathrm{Ha}$, la cual coincide parcialmente con la del sitio arqueológico, caracterizado por la distribución de materiales (principalmente cerámicos y líticos) en dicha superficie. Ante la dificultad de identificar las concentraciones de material arqueológico en el espacio cultivado, la metodología para el estudio del sitio consistió en la recuperación intensiva y sistemática de los materiales de superficie y también se realizaron trece sondeos distribuidos dentro del espacio cultivado y en los sectores sin cultivar próximos a la barranca (Figura 2). En los sectores cultivados comprobamos mediante la excavación que las operaciones agrícolas han transformado los primeros $0,35 \mathrm{~m}$, incidiendo en la integridad del registro 
y la fragmentación de los artefactos. ${ }^{3}$

A pesar de estos procesos, se determinó en las excavaciones una secuencia de ocupaciones, identificando un nivel sin intrusiones ni alteraciones correspondiente al componente alfarero medio (Siglos V-XIII) ${ }^{4}$, mientras que el nivel tardío (con cerámica Inca Viluco y Diaguita chilena inca) se encuentra muy impactado por la labranza, entre otros agentes de perturbación (Ots 2008).

Los restos estudiados fueron asociados a un espacio doméstico de residencia permanente, donde se realizaron distintas etapas del proceso de formatización y mantenimiento de artefactos líticos y se utilizaron recipientes cerámicos con distintas funciones relacionadas con actividades de obtención y preparación de alimentos (Ots 2007). Estos datos destacan a Agua Amarga como uno de los pocos sitios residenciales del piedemonte estudiados en el Centro Oeste de Mendoza, ya que la información precedente procede fundamentalmente de prospecciones y recolecciones (Canals Frau 1950, 1956, Lagiglia 1978, 1979, entre otros). Otras actividades se están considerando a partir del registro de éste y otros sitios del Valle de Uco, entre ellas la producción agrícola. Aunque la transformación del paisaje de los últimos siglos dificulta la identificación de áreas que podrían haber sido cultivadas con tecnología similar a la que aún se utiliza en la finca Agua Amarga, se han registrado artefactos de labranza en otro sitio próximo (Puesto La Isla, Ots 2007b).

\section{Descripción del caso de estudio}

En uno de los sondeos excavados en un sector no afectado por el laboreo agrícola identificamos el contexto que presentamos en este trabajo. El sondeo (SI) se ubicó sobre la barranca Sur del arroyo Agua Amarga (Figura 2), a partir del cual se realizó una prolongación hacia el E y $S$, y finalmente se agregaron otras seis cuadrículas. En la excavación de $9 \mathrm{~m}^{2}$ se registró una concentración de restos a partir de los 0,30 $\mathrm{m}$ de profundidad, en muchos casos termoalterados, y espículas de carbón. Se determinó que los materiales se encontraban depositados en una estructura poco profunda (0,30 m como máximo), termoalterada, y modificada por acción de roedores (Figura 3).

Como resultado de la excavación, pudimos definir una unidad estratigráfica fijada por un contexto espaciotemporal (Lyman 1994:8-9; Mengoni Goñalons 2010). El conjunto de restos identificados es parte de una estructura, que consideramos de grano grueso debido

\footnotetext{
3 La metodología y los resultados de la investigación en Agua Amarga pueden consultarse en Ots 2008.

4 El fechado más antiguo de este componente alfarero en el Valle de Uco es de 1470 \pm 70 (sitio Puesto Eguino, Tunuyán. Bárcena 2001b). En Agua Amarga ha sido fechado entre los siglos XII y XIII, en tanto que el componente tardío se ubica entre los siglos XIV y XVII (Ots 2007, 2009).
}

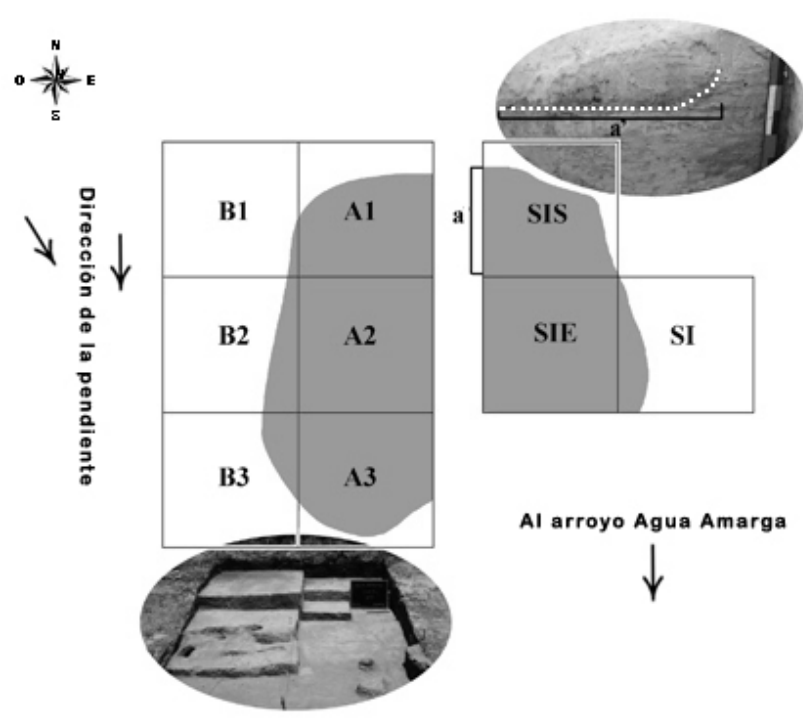

Figura 3. Esquema de ubicación de los Sondeos (I, I-Este, I-Sur) y las cuadrículas. Superficie de distribución de desechos (sombreado). Fotos: Superior: Perfil Este del Sondeo I-Sur. Destacado (puntos blancos): perfil de la estructura. Inferior: Nivel final de la concentración de material termoalterado.

Figure 3. Schematic location of Test Pits (I, I-East, I-South) and Squares. Refuse distribution (grey). Photographs: Superior, East profile od Test Pit I-South (with dots: structure profile). Inferior: Final level of thermoaltered material concentration.

a la posibilidad de ser el resultado de sucesivos eventos de depósito (Binford 1981, Mengoni Goñalons 2010).

Hemos obtenido dos fechados sobre materiales de este contexto. Entre los fragmentos de cerámica termoalterados se incluye uno decorado con engobe rojo en ambas caras (borde de recipiente cerrado restringido), características que lo adscriben tipológicamente entre la cerámica tardía local. Un fechado por TL del tiesto (UTCL 1725) lo ubica en un rango entre $530 \pm 50$ y $615 \pm 60$ años AP.

El otro fechado se realizó sobre una muestra de carbón del depósito, cuyo resultado contrasta positivamente el anterior: $450 \pm 50 \mathrm{AP} 1420-1530 \mathrm{cal}$ d.C. $(p=.05)$ y $1560-$ 1630 cal d.C. $(p=.95)$ (Beta-261727).

Estos datos ubican el contexto estudiado en un rango temporal que coincide con el momento de dominación incaica regional y el comienzo del contacto hispanoindígena. El estrecho período en el cual se produjeron la conquista incaica y española ha determinado que las fechas que se ubican dentro del lapso 1450-1650 se interpreten en relación con alguna de estas ocupaciones. El registro de éste y otros contextos estudiados por nosotros en Agua Amarga se asocia con elementos indígenas locales y no locales incaicos. En el mismo sentido, en la recolección sistemática de superficie y la excavación de sondeos, no se han identificado materiales hispano-indígenas o coloniales (Ots 2007). 


\begin{tabular}{lcccccccc}
\hline & \multicolumn{3}{c}{ Botánico } & \multicolumn{2}{c}{ Óseo } & \multicolumn{2}{c}{ Cerámico } & \multicolumn{2}{c}{ Lítico } \\
\cline { 2 - 9 } Cuadrícula & $\mathrm{n}$ & quemados & $\mathrm{n}$ & quemados & $\mathrm{n}$ & quemados & $\mathrm{n}$ & quemados \\
\hline Sondeo I & 23 & 23 & 70 & 31 & 27 & 20 & 10 & 3 \\
Sondeo I-E & 201 & 201 & 11 & 6 & 21 & 5 & 11 & - \\
Sondeo I-S & 687 & 687 & 125 & 63 & 23 & 4 & 31 & 1 \\
A-1 & 338 & 338 & 39 & 20 & 19 & 4 & 13 & - \\
A-2 & 819 & 819 & 32 & 21 & 12 & 6 & 20 & 1 \\
A-3 & 44 & 44 & 26 & 14 & 10 & 4 & 23 & - \\
B-1 & 236 & 236 & 9 & 1 & 8 & 1 & 2 & - \\
B-2 & 9 & 9 & 25 & 6 & 16 & 14 & 20 & - \\
B-3 & 4 & 4 & 12 & 6 & 12 & 2 & 3 & - \\
Total & 2361 & 2361 & 349 & 168 & 148 & 60 & 133 & 5 \\
\% termoalterados & & 100 & & 48,14 & & 40,50 & & 3,80 \\
\hline
\end{tabular}

Tabla 1. Total de restos (n) y estado de conservación (quemado) por categorías de materiales y por cuadrícula.

Table 1. Total remains (n) and preservation state (burn) by material categories and square provenience

\section{Materiales y métodos}

Los restos fueron recuperados en la excavación y mediante tamizado en seco de los sedimentos de la estructura. Aplicamos métodos y técnicas específicos para la identificación y el análisis de los distintos tipos de materiales recuperados del contexto. La mayoría se encuentran termoalterados y muy fragmentados, e incluyen restos óseos y de cáscara de huevo ${ }^{5}$, macrorrestos arqueobotánicos, fragmentos de distintos recipientes cerámicos y de instrumentos y desechos líticos (Tabla 1).

El análisis zooarqueológico tuvo como objetivo la interpretación de la variabilidad del conjunto arqueofaunístico. Se analizó tanto el perfil taxonómico y anatómico como el tafonómico de la muestra; las marcas y huellas producidas sobre los restos óseos, entre las que se incluyó la termoalteración. Para determinar la abundancia y composición de los conjuntos óseos se recurrió a los métodos de cuantificación y lineamientos metodológicos propuestos por Lyman (1994), Mengoni Goñalons (1988, 1999, 2010), Reitz y Wing (1999), entre otros.

Los macrorrestos arqueobotánicos se encuentran, en su totalidad, termoalterados. De los ejemplares recuperados fueron sometidos al análisis de identificación sólo aquellos cuyas características morfológicas permitían considerarlos como entidades independientes. Las técnicas empleadas en las identificaciones taxonómicas variaron según el género y/o especie del que se trate. Se realizaron determinaciones macroscópicas: estado del espécimen (completo o fragmentado), parte de la planta (semilla, endocarpo, fruto, vaina, etc.), dimensiones (longitud: largo máximo y central, latitud: ancho máximo y central, grosor, largo/ancho) y caracteres morfológicos diagnósticos. La

\footnotetext{
${ }^{5}$ Los fragmentos de cáscara de huevo $(\mathrm{N}=11$, sin alteración térmica) no se incluyen entre los materiales analizados en este trabajo.
}

descripción macroscópica de los ejemplares se realizó a ojo desnudo y con microscopio estereoscópico ( $2 \mathrm{X}$ a 4X). El trabajo consistió en comparar el material arqueológico con el de colecciones de referencia (actual y arqueológica), ilustraciones, claves botánicas y bibliografía específica (Abiusso y Cámara Hernández 1974, Babot et al. 2007, Burkart 1952, Oliszewski 2009, Parodi 1959, Pozner 1998, Singh et al. 1991).

De acuerdo con los objetivos del trabajo, los análisis cerámico y lítico estuvieron orientados particularmente a los atributos tecnológicos, morfológicos y físicos que pueden asociarse con la tecnofunción de los artefactos (Skibo 1992). La metodología de estudio consistió en la cuantificación y medición de las piezas y los fragmentos, y la descripción de atributos tecnológicos (de acuerdo a los criterios descriptivos de Aschero 1975 para el material lítico y Orton et al. 1997 para el cerámico). Asimismo, se consideraron las características morfológicas y las huellas de uso en aquellos casos en que pudieron identificarse a pesar de la fragmentación y el estado de conservación de los artefactos.

\section{Resultados}

\section{Análisis zooarqueológico}

El Sondeo I y sus prolongaciones se ubican fuera del terreno impactado por las tareas agrícolas -principalmente la acción del arado- por lo cual la incidencia tafonómica de las mismas es nula. Se observaron galerías subterráneas producto de la actividad de roedores, los que no incidieron de manera directa sobre los restos óseos recuperados, ya que no se identifican las marcas de roído distintivas sobre la superficie cortical de los huesos.

La fragmentación ósea se explica por procesos tafonómicos y antrópicos. En algunos casos, en particular de los especímenes de especies más grandes, tuvo su origen 


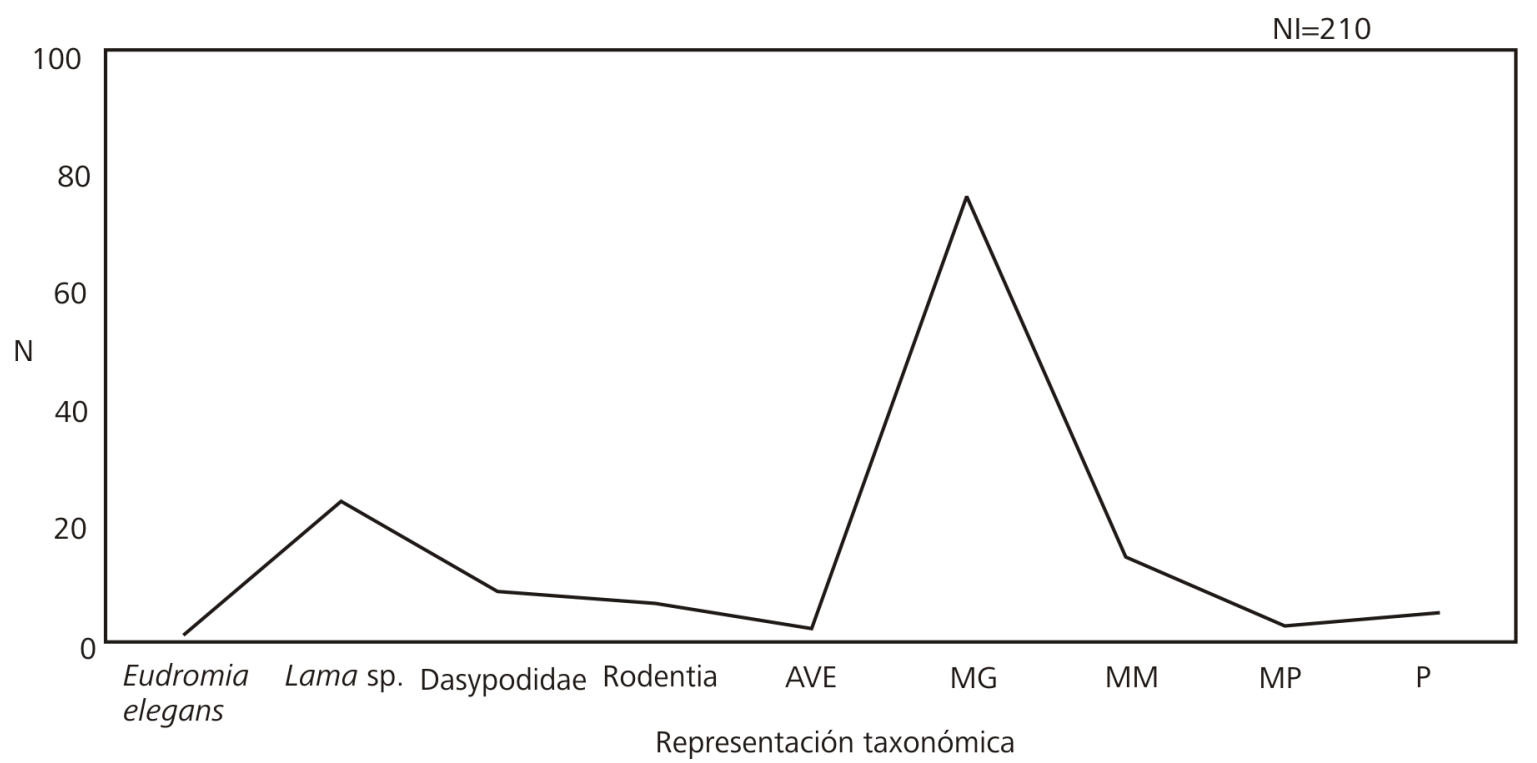

Figura 4. Análisis zooarqueológico: Identificación taxonómica.

Figure 4. Zooarchaeological analysis. Taxonomic identification.

en causas diagenéticas de diversos agentes tafonómicos entre los que podemos mencionar las raíces, el pisoteo y, en particular, el ingreso de agua -identificado en los lentes arenosos de los cortes estratigráficos- que debe haber influido en el depósito de sales sobre los restos óseos. En otros casos, la fragmentación se debió a factores antrópicos, con marcas características: escotaduras semilunares en huesos largos, fracturas transversales en primeras falanges. Es importante destacar la influencia de la alteración térmica, más que de la meteorización, sobre los patrones de fracturas producidas en el conjunto (Mengoni Goñalons 1988, 2010).

En cuanto al análisis propiamente dicho, se procuró alcanzar el mayor nivel de identificación taxonómica posible $^{6}$, y en un grado menor diferenciar la clase Mammalia por tamaño: grandes (similares a camélidos), medianos (a ovicápridos) y pequeños (a lepóridos o menores). Otro grupo poco numeroso solo pudo ser identificado como "pequeños" $(P)$, se trata de restos que pueden corresponder tanto a mamíferos como a aves. Finalmente, el subconjunto "no identificado" (NI) completó la muestra. El NISP es de 143, mientras que el NR es igual a 353.

El perfil de identificación taxonómica de la muestra se observa en la Figura 4. La riqueza taxonómica es baja (NTAXA $=4)$. La abundancia relativa muestra, a través del índice de Shannon-Weaver (Grayson 1984, Lyman 2008), que es relativamente alta $\left(H^{\prime}=1,12\right)$, con lo cual se puede hablar de un conjunto con una distribución pareja

\footnotetext{
6 En algunos casos la identificación anatómica pudo lograrse al ensamblar restos óseos muy fragmentados.
}

(even distribution) en la abundancia de las categorías taxonómicas (4) (Mengoni Goñalons 2010). Sin embargo, Lama sp. representa por su mayor volumen relativo el mayor ingreso de proteína animal en el conjunto (Wandsnider 1997: 9), más aún si consideramos los especímenes asignados como Mammalia grande, los cuales inferimos proceden de camélidos.

En la Figura 5 se señalan los porcentajes de alteración térmica de cada categoría del conjunto total, donde se observa la alta representación de esta variable.

Elementos identificados como camélidos se relacionaron respectivamente con el cráneo y con la pata trasera de un individuo muy joven y con manos y pies de un ejemplar adulto. Todos ellos sin alteración térmica, a diferencia de otros elementos de la columna vertebral que sí presentaron modificaciones por efectos del fuego. De la misma familia se pudo identificar una falange distal (1FA) que tiene un rango osteométrico aproximado a los valores de las especies de mayor tamaño (guanaco o llama), además de un canino en estado fresco que tiene una 'forma oblicua', característica del guanaco (Benavente et al. 1993).

Sabemos que el procesamiento de la carcasa animal puede dejar la impronta de marcas sobre la matriz ósea, aunque esto no siempre suceda así (Mengoni Goñalons 2010). En el conjunto analizado se observaron evidencias de marcas de procesamiento. En el caso del camélido de tamaño pequeño, se observa una fractura transversal en la diáfisis del fémur, deteriorado por incrustación de sales, con dos marcas de corte paralelas del tipo "slice" (norma posterior), destinada a la obtención de médula. 


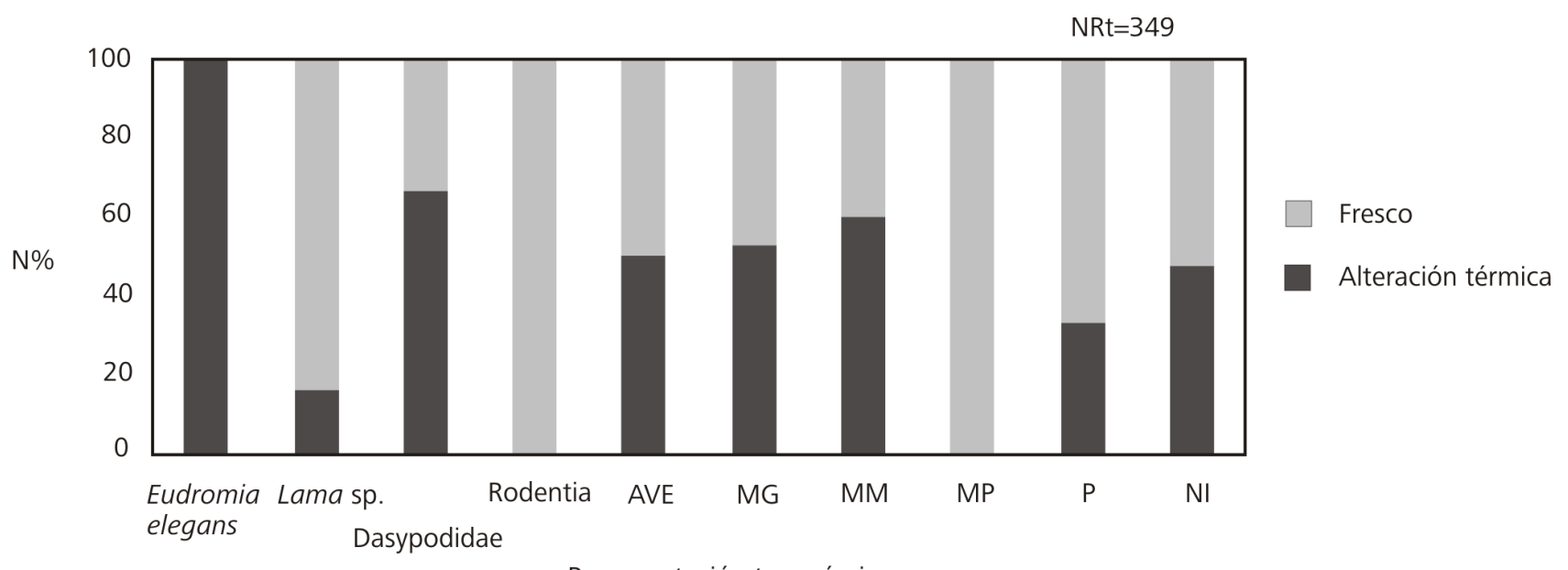

Figura 5. Análisis zooarqueológico: Alteración térmica.

Figure 5. Zooarchaeological analysis.Thermal alteration.

En una vértebra cervical (4CE), también de camélido, termoalterada y deteriorada por sales, se hallaron marcas de corte paralelas, igualmente del tipo "slice", en el tubérculo de la cresta ventral, cuyo objetivo pudo ser el descarne del hueso (músculo largo del cuello). Otras marcas de procesamiento se determinaron en especímenes identificados como mamíferos grandes: incisiones, en un caso en el cuerpo de un fragmento de costilla termoalterado, pudiendo representar la acción de cortar o tajar los tejidos blandos o el raspado de la matriz ósea con un objeto cortante (Figura 6); y en otro, en el proceso espinoso de una vértebra lumbar, también con alteración térmica.

La mayoría de las modificaciones naturales tuvieron que ver con el desgaste diagenético, acción de raíces, presión sedimentaria, etc. La meteorización pudo determinarse en algunos casos dentro de valores bajos (1-2) en la escala de Berhensmeyer (1978), indicando que los restos óseos no tuvieron una exposición prolongada en la superficie. Tanto el fémur como las tres falanges primeras identificadas como Lama sp., tienen una meteorización en dicha escala de 2. Mientras que en Mamalia (mediana y grande), en los casos posibles de su determinación $(\mathrm{N}=6)$, los estadios 1 y 2 tienen un $\mathrm{N}=3$ cada uno. Destacamos en particular la influencia que tuvieron las sales, que no solo alteraron la integridad de la matriz ósea, sino que encubrieron posibles marcas de procesamiento.

El resto del conjunto arqueofaunístico se compuso de elementos asociados con faunas de tamaño pequeño, tal el caso de un fémur de martineta (Eudromia elegans), placas de edentados y un carpometacarpo de ave, de tamaño similar a la martineta. Todos ellos mostraron evidencias de alteración térmica. Sin termoalteración fueron identificados un tibiotarso de ave de tamaño similar a la "paloma casera" y diversos especímenes de la cabeza de un roedor.
El 52\% de los especímenes identificados como mamíferos grandes exhibieron termoalteración, mientras que en los mamíferos medianos, esa variable alcanzó el 60\%. Los que se correspondieron con el estadio más pequeño no expusieron efectos de alteración térmica, mientras que para los restos óseos no identificados alcanzó el $46 \%$.

La fragmentación del conjunto óseo es alta. Para acercarnos a una estimación de la muestra analizada, utilizamos el cociente entre el Peso (g) sobre N (número de restos óseos analizados). De manera global ese cociente dio 0,48 , un valor muy bajo para el conjunto. Esta relación pudo estar influida por las especies pequeñas y los restos óseos no identificados, que son numerosos y con pesos relativamente bajos, tanto en estado fresco como termoalterados. Mientras que el cociente entre NISP/MNE (índice de fragmentación, Mengoni Goñalons 1999:63; Lyman 2008:251) para Lama sp. es 2, un

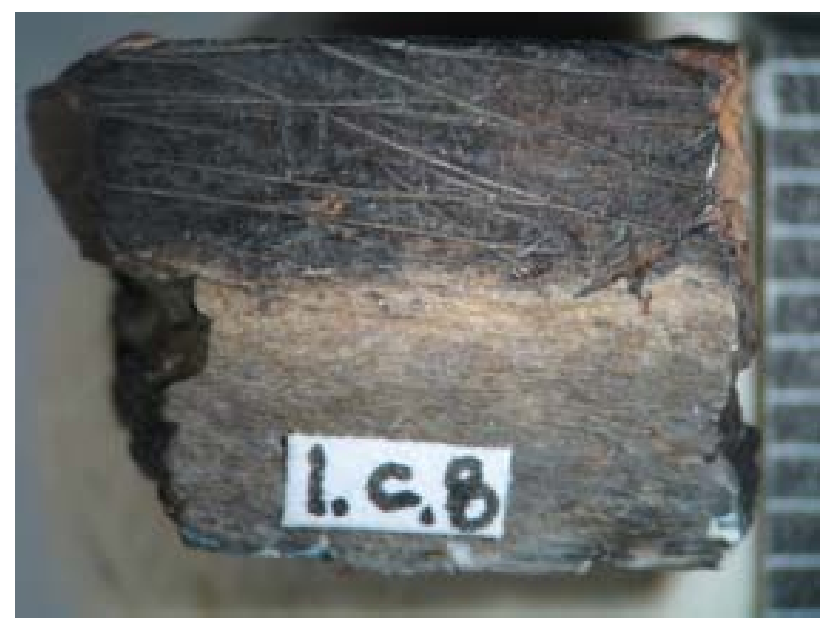

Figura 6. Análisis zooarqueológico: Fragmento con huellas de corte tipo slice.

Figure 6. Zooarchaeological analysis.bone fragment showing "slice"cutmark. 


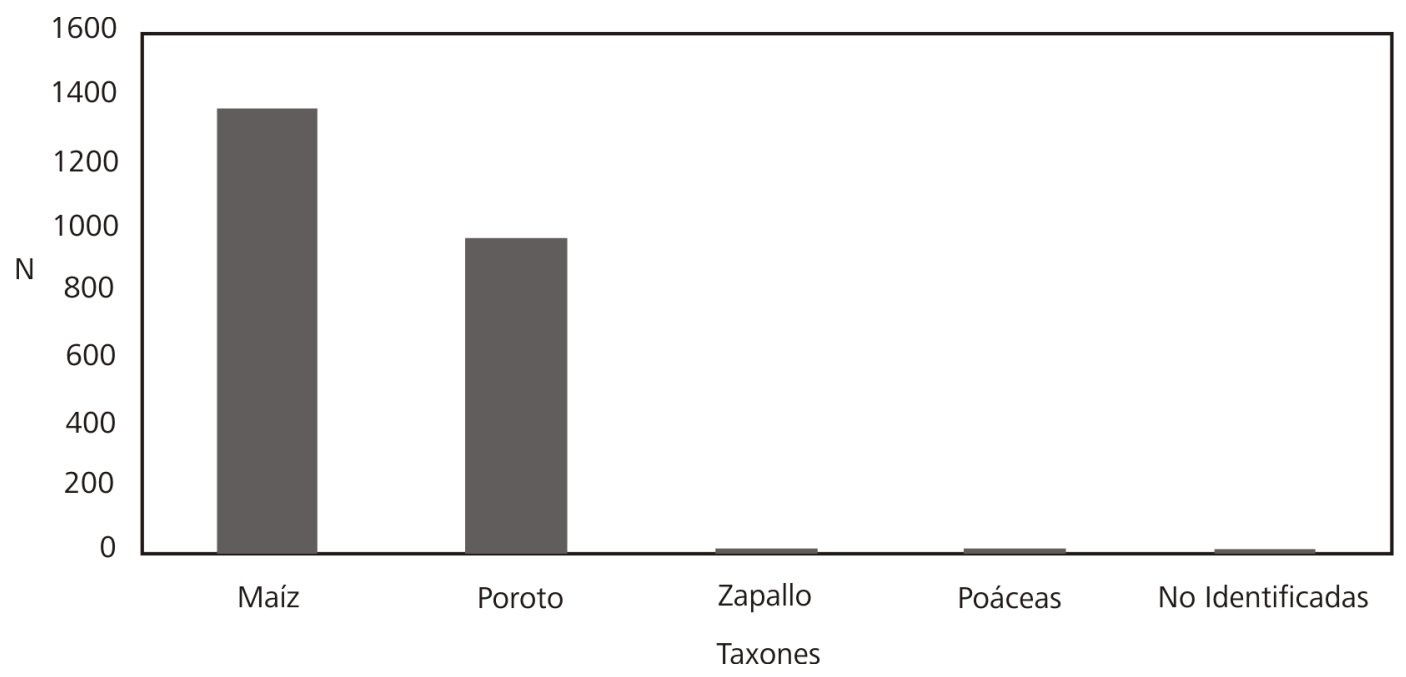

Figura 7. Análisis arqueobotánico: Taxones vegetales identificados.

Figure 7. Archaeobotanical analysis. Identified taxa.

índice relativamente alto, afectado por los fragmentos de cráneo.

El origen del conjunto óseo es antrópico para la mayoría de los restos, incluyendo tanto a los camélidos como a los taxones de menor tamaño, aves y mesomamíferos, dada la presencia de termoalteración y marcas de procesamiento. Otra parte de la muestra, aunque en menor cantidad, tiene una acumulación de origen natural -como es el caso de los roedores- a la que podríamos sumar restos óseos (cráneo) identificados como Mammalia pequeña. La asociación a causas naturales de elementos identificados como roedores (dientes, molares, mandíbulas y cráneo), sin alteración térmica, es contrastada por el hallazgo de las pequeñas galerías mencionadas anteriormente que indican que luego del abandono del depósito éste habría sido ocupado por los roedores que luego murieron in situ. Podemos caracterizar al conjunto analizado como integrando un contexto de desecho de elementos de consumo antrópico, al que se le suman posteriormente especímenes de roedores que mueren en el lugar por causas naturales.

\section{Análisis arqueobotánico}

Las condiciones de aridez de la zona en estudio determinan la dificultad de preservación de los materiales orgánicos a menos que hayan sufrido procesos de termoalteración natural o cultural. El registro arqueobotánico analizado está conformado exclusivamente por macrorrestos termoalterados que manifiestan modificaciones tanto en su forma y dimensiones como en sus caracteres morfológicos diagnósticos. Todo esto vuelve sumamente dificultosa la tarea de identificación.

Por otra parte y como resultado de las actividades de los grupos humanos, sólo se registran semillas. Botánicamente y a los efectos taxonómicos son mucho más útiles otras partes de la planta como hojas, flores o frutos. Esta parcialidad en el tipo de elementos que componen el registro arqueobotánico contribuye a dificultar la identificación taxonómica.

Como puede observarse en la Figura 7 fueron identificados en total 2361 especímenes correspondientes a Zea mays L. $(\mathrm{N}=1366: 57,85 \%)$, Poaceae $(\mathrm{N}=9: 0,4 \%)$; Fabaceae: Phaseolus vulgaris var. vulgaris $\mathrm{L}$. (N=972: $41,2 \%)$; Cucurbitaceae: Cucúrbita L. (N=6: 0,25\%) y frutos no identificados $(\mathrm{N}=8: 0,3 \%)$. En la tabla 2 se presenta la frecuencia y procedencia de los distintos taxones identificados.

A continuación presentamos un detalle de las identificaciones realizadas:

Zea mays L. "Maíz" (Abiusso y Cámara Hernández, 1974; Parodi, 1959; Oliszewski, 2009)

La muestra está compuesta por 1366 granos termoalterados en buen estado de conservación. Los granos se presentan completos e incompletos (en los que se observa la cavidad en donde se alojaba el embrión); en ambos casos es posible determinar dimensiones y forma. Además se registraron numerosos fragmentos de granos que no se contabilizaron como unidades individuales ya que no es posible determinar dimensiones y forma. Por último se registraron 6 fragmentos de marlos sin granos pero con huellas de los mismos.

Debido al estado de carbonización son muy pocas las variables que permiten acercarnos a la identificación subespecífica de Zea mays. Las variables dimensiones, forma, superficie externa y estructura interna son suficientes en este caso para asignar todos estos especímenes a Zea mays. 


\begin{tabular}{lcccccc}
\hline Procedencia & Z. mays & Poaceae & P. vulgaris & Cucurbitaceae & No identificados & Total \\
\hline SI & 18 & - & 5 & - & - & 23 \\
SI-E & 132 & - & 60 & 3 & 6 & 201 \\
SI-S & 517 & 9 & 156 & 3 & 2 & 687 \\
A-1 & 208 & - & 130 & - & - & 338 \\
A-2 & 335 & - & 484 & - & - & 819 \\
A-3 & 32 & - & 12 & - & - & 44 \\
B-1 & 124 & - & 112 & - & - & 236 \\
B-2 & - & - & 9 & - & - & 9 \\
B-3 & - & - & 4 & - & - & 4 \\
Total & 1366 & 9 & 972 & 6 & 8 & 2361 \\
\hline
\end{tabular}

Tabla 2. Procedencia de los taxones vegetales identificados.

Table 2. Provenience of identified vegetal taxa.

Las dimensiones varían entre $4-13 \mathrm{~mm}$ de longitud por 4-10 mm de latitud. Los granos presentan formas muy variables: acuminada, redondeada, alargada (predomina largo sobre ancho), cuadrangular, ancha (predomina ancho sobre largo) y combinaciones entre las anteriores. La superficie externa se presenta en general rugosa y no uniforme, agrietada por la carbonización. La estructura interna se presenta en todos los casos porosa, con oquedades, y brillosa debido a la alta composición de hidratos de carbono.

La identificación de razas se torna más dificultosa, de todos modos la gran variabilidad de tamaños permite determinar claramente la existencia de 3 grupos dentro de la muestra (Figura 8)

- Grupo A: granos grandes de forma alargada ( $N=19$; 3,4\%). Dimensiones extremas: 10,5-12 mm de longitud x 5-8 mm de latitud.

- Grupo B: granos medianos de forma predominantemente acuminada pero también redondeada, cuadrangular, alargada y ancha. ( $\mathrm{N}=467 ; 84,3 \%)$. Dimensiones extremas: 7-10 $\mathrm{mm}$ de longitud $\times$ 5-8 $\mathrm{mm}$ de latitud.

- Grupo C: granos pequeños de forma acuminada ( $N=68$; $12,3 \%$ ). Dimensiones extremas: 5-6,5 mm de longitud $x$ 4,5-6 $\mathrm{mm}$ de latitud.

Phaseolus vulgaris var. vulgaris L. "Poroto común cultivado" (Babot et al.2007; Burkart, 1952; Singh et al., 1991)

Fueron identificadas 972 semillas termoalteradas: fragmentos o cotiledones completos en su mayoría ( $\mathrm{N}=$ 941) y sólo en 31 casos especímenes completos (ambos cotiledones).

\footnotetext{
7 Debido a la gran cantidad de especímenes para realizar esta aproximación subespecífica se seleccionó una muestra representativa de las distintas cuadrículas del depósito (Sondeo I $n=4$; Sondeo I $E n=122$; Sondeo I S n=369; Cuadrícula A-1 n=10; Cuadrícula A-2 n=25; Cuadrícula A-3 n=24). La misma está compuesta por 554 granos que constituyen un $40 \%$ del total de especímenes identificados como Zea mays.
}

El estado de preservación de los especímenes es muy bueno. En general la textura se presenta lisa y la superficie uniforme. Las dimensiones varían entre 8,5-13,0 mm de longitud por 5-10 mm de latitud. Las formas que se encuentran son reniforme $(55,9 \%)$, ovalada $(26,8 \%)$ y alargada $(17,3 \%)$.

Si bien la ausencia de caracteres morfológicos diagnósticos dificulta la identificación, las variables forma y dimensiones son suficientes para adscribir a todos los especímenes dentro de la forma doméstica del poroto común.

\section{Cucurbita L. "Zapallo" (Parodi, 1966; Pozner, 1998)}

Se registraron seis semillas termoalteradas en muy buen estado de conservación que se pueden adscribir al género Cucúrbita y que probablemente correspondan a la forma doméstica de zapallo (Cucúrbita maxima Duch.).

Las dimensiones de las semillas varían entre 11-15 mm de longitud x 6-7 mm de latitud x 4-2 $\mathrm{mm}$ de grosor. La forma es elíptica en todos los casos, la superficie uniforme y la textura lisa.

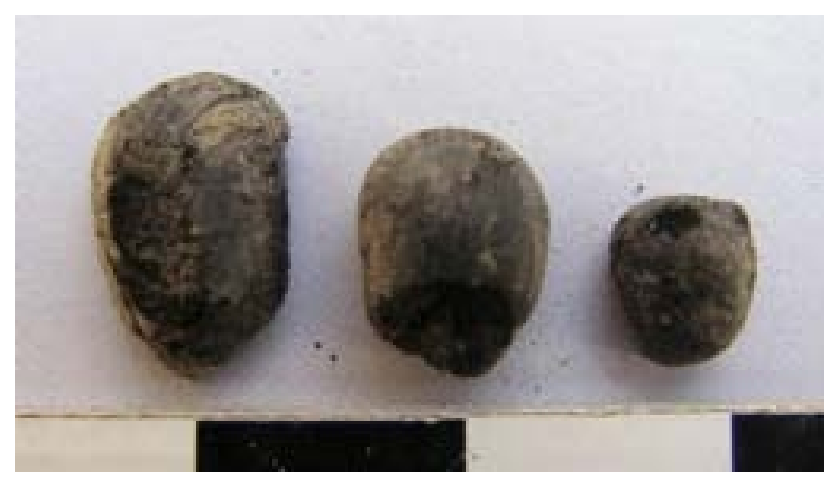

Figura 8. Análisis arqueobotánico: Granos de maíz, de izquierda a derecha: grupo A (grande), grupo B (mediano) y grupo C (pequeño).

Figure 8. Archaeobotanical analysis. Maize grains, from left to right: Group A (big), Group B (medium,) and Group C (small). 


\section{Poaceae}

Se identificaron 9 semillas de forma elíptica de entre 7-11 $\mathrm{mm}$ de longitud por 3-5 mm de latitud. En base a la forma y las dimensiones, estimamos que estos especímenes podrían pertenecer al género Bromus (Gutiérrez y Pensiero 1998).

\section{No identificados}

En esta categoría se inscriben 8 frutos de forma ovalada de entre 9-11 $\mathrm{mm}$ de longitud por 8-9 $\mathrm{mm}$ de latitud y 6,5-8 $\mathrm{mm}$ de grosor.

Análisis cerámico y lítico: tecnofunción, tipología y estado de conservación

La muestra de cerámica del contexto es de $\mathrm{N}=148$ tiestos. Consideramos dos medidas para comparar tamaño de los tiestos: el peso y el espesor. La fragmentación es muy alta, con tiestos de tamaño muy pequeño, cuyo promedio de peso es $\mathrm{x}=2,56 \mathrm{~g}(\mathrm{~S}=3,05)$; si bien el rango de peso es amplio $(0,21 / 24,08)$, el $75 \%$ de los fragmentos pesa menos de $3 \mathrm{~g}$ (Figura 9). El espesor promedio de la muestra es de $0,65 \mathrm{~cm}(\mathrm{~S}=1,17$; rango $0,45 / 1,4)$.

La fragmentación de la muestra limita las posibilidades de identificar formas, por lo que distinguimos dos grandes categorías: abiertas $(3,4 \%)$ y cerradas $(96,6 \%)$, definidas a partir de atributos como tratamiento de superficies, espesor, concavidad y proyección de la curvatura.

Distinguimos dos grupos por color de la pasta y las superficies: naranja y gris o marrón grisáceo. Los fragmentos anaranjados $(\mathrm{N}=15$, de los cuales 8 tienen engobe naranja o rojo) son muy similares a nivel tecnológico: acabado de ambas superficies bien alisado, pastas compactas con escasas inclusiones de arena y partículas blancas, algunas de tamaño muy grande, índice de absorción (IA\%) promedio 15,1\% $(S=0,1)$. Cuatro tiestos de este grupo están termoalterados, uno de ellos corresponde al borde y cuello de un recipiente restringido, de pasta marrón rojiza y engobe rojo en ambas caras, y fue utilizado para el fechado por termoluminiscencia descrito supra. Las características mencionadas incluyen a la cerámica de este grupo dentro de las piezas cerradas (ollas, aribaloides, recipientes restringidos de fondo plano) de estilo Viluco inca, asignación contrastada con los fechados antes mencionados. En este grupo, sólo dos tiestos corresponden a la misma unidad de análisis, y podrían pertenecer a la misma pieza, aunque no remontan entre sí.

El grupo más numeroso está compuesto por tiestos de pasta gris o marrón grisácea con superficies alisadas, sin decoración. Dentro de este grupo hay mayor diversidad en cuanto a atributos tecnológicos como espesor, color aparente de superficies y pastas y composición de las materias primas, sin embargo se mantienen dentro de rangos que nos permiten incluirlas en el mismo conjunto. El remontaje de tiestos con atributos similares ha sido posible en pocos casos. Como características generales, las pastas tienen textura porosa, composición medianamente densa de inclusiones de arena, cuarzo $y$, en algunos casos, mica, de tamaño fino a grueso, esfericidad alta, aspecto subanguloso o subredondeado y distribución equilibrada (de acuerdo a los criterios de Orton et al. 2007). La frecuencia de tiestos que presentan termoalteración en este grupo en una o ambas caras es alta (43\% de la muestra) (Figura 9). La porosidad aparente, o IA\% promedio del grupo es de 10,9\%.

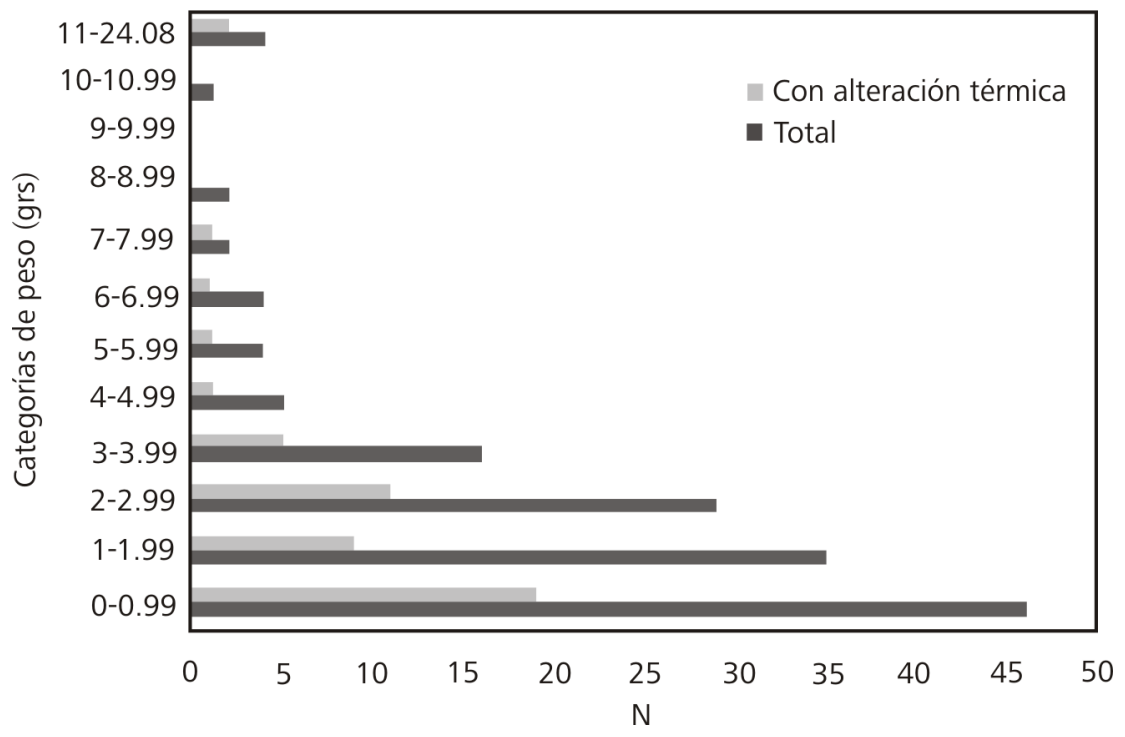

Figura 9. Análisis cerámico: frecuencia de fragmentos por categoría de peso y estado de conservación.

Figure 9. Ceramic analysis. Fragment frequency sorted by weight category and preservation state. 


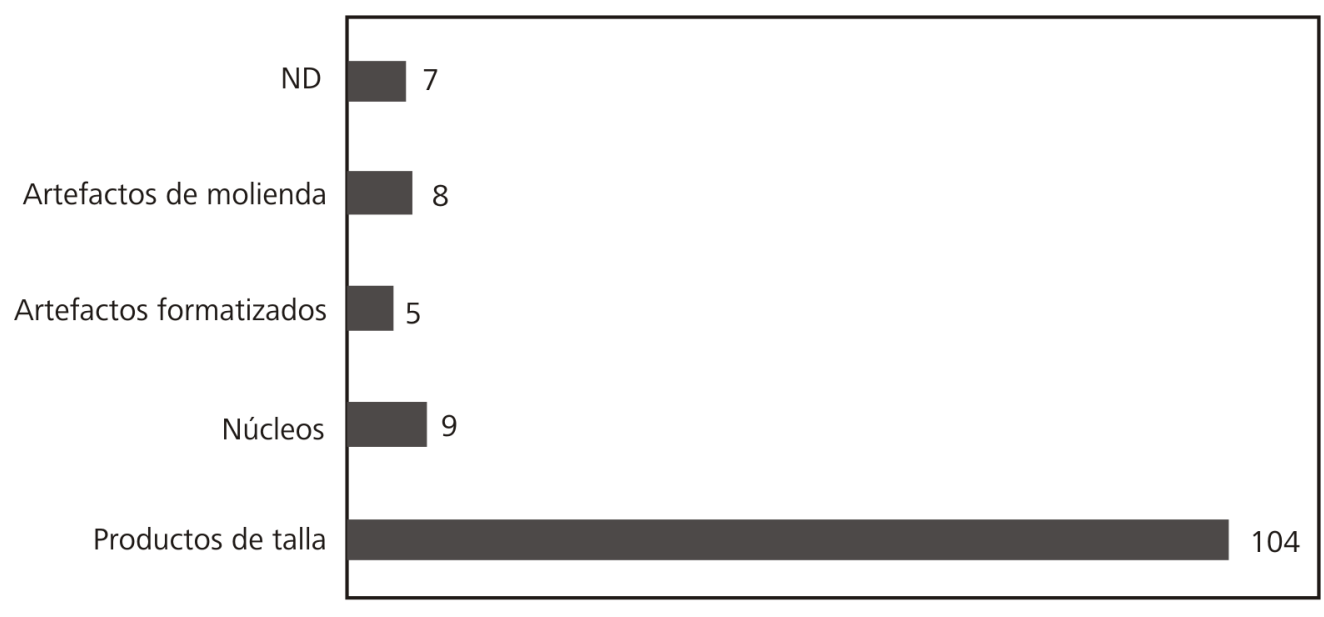

$\mathrm{N}$

Figura 10. Análisis lítico: composición del conjunto.

Figure 10. Lithic analysis. Assemblage composition.

El conjunto total de material lítico recuperado está compuesto por 133 piezas entre talladas y pulidas: artefactos de molienda, artefactos formatizados, núcleos y productos de talla (desechos y microdesechos) (Figura 10).

Entre los artefactos de molienda incluimos manos completas (1) y fragmentadas (5) y fragmentos de conanas (2), elaborados en granito rosado y gris. Las formas de las manos son ovaladas, planas; la que se conserva completa presenta marcas y está quemada. La forma de los artefactos pasivos se ha inferido por comparación con piezas completas del área ("conanas"), ya que el tamaño de los fragmentos no permite determinar su morfología integral, éstos no presentan termoalteración.

Los artefactos formatizados (3,8\% del total de la muestra) están representados por tres raspadores y un perforador de cuarzo que presentan signos de termoalteración, y una punta triangular, muy pequeña, con aletas, de cuarcita. Este tipo de puntas también son asignadas, en la región, a las ocupaciones tardías o contemporáneas a la ocupación incaica regional (entre otros, García 1992). El resto del conjunto lítico está compuesto por desechos de talla de variados tamaños, en algunos casos también termoalterados, y sin posibilidad de remontaje.

Otros fragmentos de rocas $(n=5)$ presentan signos de exposición al fuego, en uno de los casos posterior a la fragmentación, y los incluimos en la categoría de "piedras de fogón" (Aschero 1975). Si bien se encuentran distribuidos en distintos sectores de la estructura, los fragmentos de rocas e instrumentos de mayor tamaño se concentran en la base, en la cuadrícula A-2.

En los conjuntos cerámico y lítico no hemos identificado otras huellas de uso además de la alteración térmica, o marcas, ya que no se conservan residuos macroscópicos.

\section{Discusión}

\section{Estrategias de consumo y descarte en Agua Amarga}

Interpretamos el conjunto analizado como un depósito secundario de desechos de actividades relacionadas con la alimentación. Este tipo de contextos se caracteriza por la alta acumulación y la densidad de los materiales descartados (Wilson 1994). La cantidad y diversidad de restos, sobre todo botánicos, y el estado de conservación de los mismos sostiene esta interpretación sobre otras posibles (vg. un fogón). En la excavación identificamos una estructura de sedimento compacto y termoalterado de aproximadamente $30 \mathrm{~cm}$ de profundidad que contenía restos en gran parte termoalterados: cerámicos, líticos, óseos y botánicos. Aunque están distribuidos por toda la superficie de la estructura hay una mayor concentración de restos óseos y vegetales en las cuadrículas $A-1, A-2$ y en los sondeos de ampliación Este y Sur del Sondeo I.

No se identificaron cenizas, y la presencia de carbón es escasa, lo que sugiere la posibilidad de que los restos hubieran sido sometidos a calor indirecto, sin descartar que pudieran haber sido quemados en otro sector del sitio y desechados finalmente en este depósito. Los macrorrestos botánicos se han conservado termoalterados y, en muchos casos, enteros, lo cual sugiere, por un lado, que debieron estar cocidos antes de la alteración térmica (la variedad "dura" de maíz hubiera reventado cruda), y por otro, que la cocción debió ser reductora, ya que de otra manera se hubieran convertido en ceniza en lugar de conservarse carbonizados. Similar observación podemos hacer respecto del material óseo, ya que entre los restos con alteración térmica ésta es completa, no parcial (como suele observarse en los casos de restos asociados a los fogones) en tanto que es bajo el porcentaje de restos que se conservan calcinados. Las piedras termoalteradas (que interpretamos como "piedras de fogón") están 
fragmentadas. Otro dato que sostiene el supuesto de que el contexto es producto de actividades de mantenimiento de otras áreas es el escaso remontaje de restos óseos y fragmentos cerámicos y líticos.

En la definición de los depósitos secundarios de desechos es importante la localización del mismo en relación con otras áreas de actividad (Wilson 1994, Tani 1995). Pocos antecedentes se conocen en el área (Norte y Centro de Mendoza) sobre el patrón residencial (en base, sobre todo, a las descripciones etnohistóricas y escasos hallazgos arqueológicos. Bárcena 2001, Cortegoso 2006). Sin embargo, suponemos que un fogón estaría asociado a otras estructuras, y no identificamos piso u otros rasgos que pudieran asignarse a una habitación, lo cual sostiene nuestra idea de que el contexto excavado es más bien un vertedero de restos de comida y/o de limpieza de fogones, donde la superposición de basura (incluyendo probablemente líquidos) produjo una combustión reductora e incompleta de los restos.

Otros restos recuperados en el contexto no presentan manifestaciones de exposición al fuego, lo que nos sugiere distintos eventos de descarte. No identificamos niveles de depositación, seguramente alterados por la acción de roedores documentada en la excavación.

El análisis del registro sostiene la relación que establecemos con actividades domésticas, especialmente culinarias de procesamiento, consumo y desecho de alimentos. La gran diversidad de residuos es característica de las actividades de elaboración y conservación propias de los lugares de residencia (Nelson 1991). Las características tecnológicas y las condiciones de conservación de la cerámica y los instrumentos líticos así lo sostienen. En comparación con la totalidad de la muestra estudiada en el sitio (con un porcentaje de cerámica quemada en 3,7\%), el $40 \%$ de los fragmentos de recipientes cerámicos recuperados en este contexto están termoalterados en una o ambas superficies, lo que sugiere su funcionalidad para cocción, además de la alteración térmica posterior al descarte.

El grupo de cerámica de pasta anaranjada que podría relacionarse más bien con otros contextos -de almacenaje o de servicio, ceremonial o funerario, como se ha documentado en éste y otros sitios (Lagiglia 1978)representa sólo el 10\% en este conjunto. La fragmentación de la muestra sólo permitió inferir algunas características morfométricas esenciales de las vasijas de cocina en el grupo mayoritario (pastas grises), que son pequeñas y de formas globulares. También se identifican otros atributos de este tipo de recipientes, como el espesor relativamente delgado de las paredes y el acabado sencillo de las superficies, sin tratamientos posteriores al alisado ni apéndices (Henrickson y Mc Donald 1983, Schiffer et al. 1994).

Las características de performance de la cerámica relevantes para la actividad de cocinar sobre fuego abierto incluyen la efectividad calórica, la resistencia al impacto y la resistencia al choque térmico. El agregado de grandes cantidades de antiplásticos minerales a las vasijas de cocina afecta a una serie de propiedades formales que incrementan la resistencia al choque térmico y la efectividad calórica, aunque disminuyen la resistencia al impacto (Bronitsky y Hamer 1986, Feathers 1989, Shiffer y Skibo 1987, Skibo et. al 1989). Esta limitación no es un problema en poblaciones con movilidad residencial reducida, como la que estamos estudiando (Ots 2007). Hemos observado estas características tecnofuncionales en la mayoría de los tiestos que corresponden a recipientes de pastas porosas, con alta densidad de inclusiones medianas a grandes de arena y cuarzo.

Si bien la mayoría del conjunto lítico está compuesto por desechos de talla, destacamos el descarte de herramientas con funciones de procesamiento de alimentos: fragmentos de manos de moler y conanas, también termoalterados. Aunque no se observan residuos macroscópicos, se podrán realizar análisis de residuos microscópicos a los restos cerámicos y líticos para complementar estos estudios.

Del análisis óseo se desprende la presencia de camélidos, que representarían el principal recurso de proteína animal, junto a otras especies de menor tamaño propias del registro regional. En el conjunto arqueológico hallado en el ámbito de descarte se incluyen especímenes con alteración térmica y algunos con marcas de procesamiento.

Si bien el conjunto arqueofaunístico es relativamente pequeño, no deja de ser interesante la presencia de elementos óseos correspondientes a las categorías neonatos o juveniles y adultos de Lama sp. Esos restos están en concordancia con el manejo de producción mixto de acuerdo a estudios etnográficos actuales (Yacobaccio et al. 1998), lo cual pudo significar la posibilidad de complementar el recurso pastoril con el de la caza. Esta última actividad se ve reflejada también en algunas especies menores, comunes en los sitios arqueológicos regionales, tales son los casos de aves como la martineta (Eudromia elegans) y mamíferos pequeños como los edentados (Garcia Llorca y Cahiza 2007). Los elementos anatómicos, identificados como pertenecientes a camélidos o mamíferos grandes, como falanges, astillas de huesos largos, costillas, entre otros, concuerdan con esta idea de complementariedad en la obtención del recurso proteico animal (Garcia Llorca y Cahiza 2007).

Nos interesa destacar especialmente los resultados del análisis arqueobotánico. El 99\% de los especímenes identificados corresponden a recursos cultivados: maíz, poroto y zapallo. Teniendo en cuenta además el contexto de hallazgo suponemos que son desechos de consumo alimenticio. Es interesante discutir el hallazgo 
de centenares de granos de maíz y semillas de poroto quemados ya que en ambos casos se trata de la parte comestible de estas plantas. Es posible pensar en dos hipótesis alternativas: que se trate de especímenes que por algún motivo fueron sometidos a calor indirecto en el lugar de almacenamiento; o que los granos y semillas estuvieran cocidos antes de la termoalteración, hipótesis que ya discutimos y que consideramos más adecuada debido al estado de conservación del registro. Esta última observación es interesante en cuanto supone estrategias de consumo, ya que se trataría del desecho de alguna comida (o de varias comidas) que incluía una combinación de maíz, poroto, zapallo y carne, en el caso de que una parte de los restos óseos analizados provinieran del mismo evento. La ausencia en el registro arqueobotánico de recursos vegetales alimenticios silvestres identificados en la zona, como algarrobo o chañar, apoya esta última hipótesis (ya que éstos suelen consumirse frescos, sin cocción previa). Maíz, zapallo y poroto conforman la denominada "trilogía americana" característica de la dieta prehispánica, por lo cual no sería extraño que en el presente caso hayan estado combinados formando parte de un mismo plato. Aunque llama la atención la dimensión de la muestra, eventos especializados, por ejemplo las fiestas, pueden producir una gran cantidad de desechos en un período de tiempo acotado (Wilson 1994: 51).

El maíz merece una mención aparte ya que la gran cantidad de especímenes recuperados y su variabilidad de tamaños permitieron determinar la existencia de tres grupos distintos dentro de la muestra. Aún cuando no es posible con estos resultados asignar los especímenes a determinadas razas, creemos que es válida la comparación con las razas establecidas para el NOA con el objeto de postular hipótesis acerca de la alta variabilidad observada. De acuerdo a la forma y a las dimensiones los especímenes del grupo A (Figura 8) podrían asignarse a maíces harinosos (tipo Capia), los maíces del grupo B a maíces semi-duros (tipo Morocho) y los maíces del grupo C a maíces duros (tipo Pisingallo). Sin entrar en la identificación de razas el planteo anterior indica que el registro arqueobotánico de Agua Amarga está constituido por maíces pequeños duros, maíces medianos semi-duros y maíces grandes harinosos que implican actividades diferentes. La probable presencia de diferentes razas de maíz, con distintos momentos de maduración supone que pudieron haberse sembrado y cosechado en diferentes momentos y/o pudieron haberse utilizado para preparar distintos tipos de comidas y bebidas. Ya sea que hayan sido cultivados in situ u obtenidos por intercambio esto implica la implementación de estrategias programadas en cuanto a momentos diferenciales de siembra y cosecha.

Producción y consumo de maíz en el Centro-Oeste de Mendoza

Además de destacar la diversidad de especies descartadas (seguramente también consumidas) y de artefactos asociados a las prácticas de procesamiento de alimentos, nos interesa retomar la discusión sobre la importancia de los productos cultivados, y particularmente del maíz como recurso económico prehispánico.

En las últimas décadas se ha estudiado con especial interés la importancia de este recurso en la producción y consumo por parte de las poblaciones indígenas del Sur y Norte de Mendoza. Sin embargo, los más recientes trabajos para este último sector sostienen por un lado que el maíz era significativamente importante en la dieta (Gil et al. 2009) y la producción local (Johnson et al. 2009), mientras que por otro (Chiavazza y Mafferra 2007) ponen en duda el hecho de que las poblaciones prehispánicas del sector hayan sido agricultoras e inclusive consumidoras de maíz y otros productos americanos.

Para el Norte y Centro de Mendoza Johnson et al. (2009) consideran, a partir de las variables temperatura (promedio anual superior a $12,7^{\circ}$ ), precipitaciones (predominantes en primavera/verano) y a la densidad demográfica previa al momento de la conquista española (superior a 27 personas cada 100 km²), que el área habría sido totalmente apta para el desarrollo e intensificación de la agricultura del maíz.

En el caso que aquí presentamos, la presencia de más de mil granos de maíz que constituyen cerca del $60 \%$ del registro arqueobotánico no es suficiente para postular su cultivo in situ. Sin embargo, el registro de Agua Amarga y otros sitios tardíos (o más bien, multicomponentes) próximos incluyen la presencia de restos de productos cultivados (que incluyen diferentes razas de maíz) y herramientas de cultivo, en zonas potencialmente aprovechables con una tecnología simple para la producción agrícola (Ots 2007). Los datos documentales también indican la presencia de espacios de producción agrícola en el Valle de Uco en el momento del contacto hispano-indígena, aunque aun no se establece la ubicación precisa de dichas tierras (Ots 2009). Por último, en el área de estudio (cuenca del río de Las Tunas) se han identificado cambios en el patrón de asentamiento en el tardío que podrían vincularse con la intensificación agrícola (Gil 1997-1998): reocupación y aumento del tamaño y la concentración de los sitios en la cota de 1000 msnm en el sector de transición entre piedemonte y llanura (Ots 2007). Esta zona se caracteriza asimismo por las condiciones ambientales propicias para la agricultura del maíz acotada a la estación estival (temperatura, precipitaciones, altura). Una reflexión similar nos sugiere la presencia de numerosos cotiledones de poroto común que constituyen más del $40 \%$ de los macrorrestos arquebotánicos. Phaseolus vulgaris var. vulgaris es un cultivo mesotérmico típico de los valles y faldas templadas sudamericanas que prospera entre los 0 y 2000 msnm (Tapia 1990).

La evidencia disponible, entonces, permite sostener que pudo haberse practicado el cultivo de maíz (entre otros 
productos) en Agua Amarga, hipótesis que deberá ser contrastada con futuros trabajos en el área.

\section{Conclusiones}

Algunas propuestas sobre las actividades de subsistencia de las poblaciones locales de Cuyo generalizaron la adopción de estrategias mixtas, sin considerar la variabilidad regional, e incluyendo al Valle de Uco. Si bien se están incorporando nuevas y fructíferas líneas de investigación, consideramos que nuestro conocimiento sobre el tema es escaso hasta el presente, y que requiere ampliar los datos disponibles. En este sentido, el caso que presentamos es un aporte en esta discusión, en cuanto complementa la información que se obtiene con otros métodos para estudiar la dieta y la subsistencia.

Pudimos confirmar la caracterización de Agua Amarga como un sitio de actividades múltiples, donde además de los contextos funerarios se identifican áreas con otros usos. El contexto estudiado fue definido como un depósito secundario de residuos producto de la limpieza de otros sectores y vertedero de restos de comidas compuestas por carnes y vegetales cultivados, entre otros bienes asociados con la alimentación.

En relación con la ocupación prehispánica tardía del sitio, discutimos, a partir del análisis de estos restos, prácticas asociadas con el procesamiento de alimentos y su consumo, integradas por diversidad de bienes y recursos faunísticos (de alto y bajo rendimiento, probablemente una complementación de recursos pastoriles con la caza) y botánicos (especialmente, cultivados) que pudieron ser obtenidos o producidos en el área donde se ubica el sitio.

La abundancia y diversidad del recurso maíz (del cual pudieron identificarse tres razas) confirma las expectativas sobre estrategias de subsistencia de las poblaciones del Norte y Centro de Mendoza del momento de contacto que ofrecen tanto las descripciones españolas tempranas como los recientes estudios bioantropológicos que destacan su relevancia en la dieta de dichos pobladores.

Mendoza, 27 de julio de 2010

\section{Agradecimientos}

El presente trabajo se realizó en el marco del proyecto "Investigaciones arqueológicas y etnohistóricas en el Centro oeste argentino" (CONICET), dirigido por el Dr. Roberto Bárcena. Agradecemos a los propietarios de la finca Agua Amarga, Sres. Ramón y José Hinojosa la autorización y predisposición para hacer las excavaciones, al Dr. Jorge Martínez la lectura y sugerencias sobre el análisis del material lítico, al Prof. Juan Pablo Aguilar su colaboración con las figuras y a los/as evaluadores/as, cuyas observaciones contribuyeron a mejorar la versión final del artículo.

\section{Bibliografía}

Abiusso, N., J. Cámara Hernández. 1974. Los maíces autóctonos de la Quebrada de Humahuaca (Jujuy, Argentina), sus niveles nitrogenados y su composición en aminoácidos. Revista de la Facultad de Agronomía. La Plata. Tomo L (1-2): 1-25.

Aschero, C. A. 1975. Ensayo para una clasificación morfológica de artefactos líticos. Aplicada a estudios tipológicos comparativos. Informe CONICET, Ms.

Babot, M. del P., Oliszewski, N. y A. Grau. 2007. Análisis de caracteres externos e internos de Phaseolus vulgaris (Fabaceae, Papilionoideae). Una comparación entre sus formas silvestre y cultivada en el Noroeste argentino. Argentina. Darwiniana, 45(2): 149-162.

Bárcena, J. R. 2001. Prehistoria del Centro-Oeste argentino. E. E. Berberián y A. E. Nielsen (eds.) Historia Argentina Prehispánica, II. Pp. 561-634. Brujas, Córdoba.

Bárcena, J. R. 2001b. Antiguos pobladores de Tunuyán. Diario Los Andes, 24-07-2001.

Behrensmeyer, A. K. 1978. Taphonomic and ecologic information from bone weathering. Paleobiology, 4: 150-162.

Benavente A., M. A., L. Adaro A., O. Gecele C. y C. Cunazza P. 1993. Contribución a la determinación de especies animales en Arqueología: familia Camelidae y taruca del Norte. Serie Programas de Desarrollo III. Universidad Nacional de Chile, Santiago de Chile.

Bibar, G. de. 1966 [1558] Crónica y relación copiosa y verdadera de los Reynos de Chile. Tomo II. Fondo histórico y bibliográfico José Toribio Medina, Santiago de Chile.

Binford, L.R. 1981. Bones: Ancient Men and Modern Myths. Academic Press. New York.

Bronitsky, G., R. Hamer. 1983. Experiments in ceramic technology: the effects of various tempering materials on impact and termal-shock resistance. American Antiquity, 51(1): 89-101.

Burkart, A. 1952. Las leguminosas argentinas silvestres y cultivadas. Segunda edición. ACME S. A., Buenos Aires.

Cortegoso, V. 2006. Comunidades agrícolas en el Valle de Potrerillos (NO de Mendoza) durante el Holoceno tardío: organización de la tecnología y vivienda. Intersecciones, 7: 77-94.

Canals Frau, S. 1950. Exploraciones arqueológicas en el Antiguo Valle de Uco (Mendoza). Publicaciones. Instituto 
de Arqueología, Lingüística y Folklore Dr. Pablo Cabrera, XXII: 1-28.

Canals Frau, S. 1956. Algunos aspectos de la cultura de Agrelo (provincia de Mendoza). Anales de Arqueología y Etnología, XII: 7-18.

Chiavazza, H., L. Mafferra 2007. Estado de las investigaciones arqueobotánicas en Mendoza y sus implicancias en la Arqueología histórica. Revista de Arqueología Histórica Argentina y Latinoamericana, 3: 129-151.

Feathers, J. K. 1989. Effects of temper on strength of ceramics: Response to Bronitsky and Hamer. American Antiquity, 54 (3): 579-588.

García, E. A. 1992. Hacia un ordenamiento preliminar de las ocupaciones prehistóricas agrícolas precerámicas y agroalfareras en el N.O. de Mendoza. Revista de Estudios Regionales, CEIDER, 10: 7-34.

Garcia Llorca, J., P. Cahiza. 2007. Aprovechamiento de Recursos faunísticos en las lagunas de Guanacache (Mendoza, Argentina). Análisis zooarqueológico de la Empozada y Altos de Melién II. Chungara, 39 (1): 117-133.

Gil, A. 1997-98. Cultígenos prehispánicos en el Sur de Mendoza. Discusión en torno al límite meridional de la agricultura andina. Relaciones de la Sociedad Argentina de Antropología, 22-23: 295-318.

Gil, A. F., R. H. Tykot, G. Neme y N. R. Shelnut. 2006. Maize on the frontier. Isotopic and macrobotanical data from central-western Argentina. Staller, J., R. Tykot y B. Benz (eds.) Histories of maize. Multidisciplinay Approaches to the Prehistory, Linguistics, Biogeography, Domestication and Evolution of Maize. Pp. 199-214. Academic Press, Burlington, Massachusetts.

Gil, A., G. A. Neme, R. H. Tykot, P. Novellino, V. Cortegoso y V. Durán. 2009. Stable Isotopes and maize Consumption in Central Western Argentina. International Journal of Osteoarchaeology, 19 (2): 215-236.

Grayson, D. K. 1984. Quantitative Zooarchaeology. Topics in the Analysis of Archaeological Faunas. Academic Press, Washington.

Gutiérrez, H. F., Pensiero, J. F. 1998. Sinopsis de las especies argentinas del género Bromus (Poaceae). Darviniana, 35: 75-114.

Gutiérrez de Manchón M.J., M.E. Furlani de Civit. 1997. Decisiones empresariales y fragilidad ambiental. Furlani de Civit, M.E. y Gutiérrez de Manchón, M.J. (comp.): Mendoza, una geografía en transformación, II. Pp. 233243. Facultad de Filosofía y Letras, Universidad Nacional de Cuyo. Mendoza.
Henrickson, E. F., M. M. McDonald. 1983. Ceramic form and function: An ethnographic search and an archaeological application. American Anthropologist, NS, 85(3): 630-643.

Johnson, A., A. Gil, G. Neme y J. Freeman. 2009. Maíces e intensificación: explorando el uso de los marcos de referencia. G. López y M. Cardillo (eds.) Arqueología y Evolución. Teoría, metodología y casos de estudio. Pp. 23-44. SB, Buenos Aires.

Lagiglia, H. 1978. La cultura de Viluco del Centro Oeste argentino. Actas y Memorias del IV Congreso Nacional de Arqueología Argentina (Primera parte). Revista del Museo de Historia Natural de San Rafael: 227-265.

Lagiglia, H. 1979 (1977) Dinámica cultural del Centrooeste y sus relaciones con áreas aledañas argentinas y chilenas. Actas del VII Congreso de Arqueología de Chile, Vol II: 531-560. Santiago de Chile.

Lagiglia, H. 2001. Los orígenes de la agricultura en la Argentina. Berberián, E. y A. Nielsen Historia Argentina Prehispánica, TI. Pp: 41-81. Brujas, Córdoba.

Lyman, R. L. 1994. Vertebrate Taphonomy. Cambridge University Press. New York.

Lyman, R. L. 2008. Quantitative Paleozoology. Cambridge University Press. New York.

Mengoni Goñalons, G. L. 1988. Análisis de materiales faunísticos de sitios arqueológicos. Xama, 1: 71-120.

Mengoni Goñalons, G. L. 1999. Cazadores de Guanaco de la estepa patagónica. Colección Tesis Doctorales. Sociedad Argentina de Antropología. Buenos Aires.

Mengoni Goñalons, G. L. 2010. Zooarqueología en la práctica: algunos temas metodológicos. Xama, 19-23: 83-113.

Michieli, C. T. 1983. Los Huarpes protohistóricos. Instituto de Investigaciones arqueológicas y Museo de la Facultad de Filosofía, Humanidades y Artes de la Universidad Nacional de San Juan. San Juan.

Nelson, M. 1991. The study of technological organization. M. B. Schiffer (ed.) Archaeological Method and Theory, 3. Pp. 57-100. The University of Arizona Press, Tucson.

Novellino, P, V. Durán y C. Prieto. 2003. Cápiz Alto: aspectos bioarqueológicos y arqueológicos del cementerio indígena de época post-contacto (provincia de Mendoza, Argentina). Paleopatología, 1.

Novellino, P., A. Gil, G. Neme y V. Durán. 2004. El consumo de maíz en el Holoceno tardío del oeste 
argentino: isótopos estables y caries. Revista Española de Antropología Americana, 34: 85-100.

Orton, C., P. Tyers y A. Vince. 1997. La cerámica en Arqueología. Barcelona, Crítica.

Ots, M. J. 2007. "La presencia incaica en el Valle de Uco, Mendoza". Facultad de Filosofía y Letras, Universidad Nacional de Cuyo, Rca. Argentina. 322p.

Ots, M. J. 2007b. La dinámica ocupacional en la frontera Suroriental del Tawantinsuyu y el imperio español: Valle de Uco, Mendoza. Actas del XVI Congreso Nacional de Arqueología Argentina, TI. Pp: 521-527. Universidad Nacional de Jujuy.

Ots, M. J. 2008. Estudio de alteraciones provocadas por laboreo agrícola sobre conjuntos cerámicos en el sitio arqueológico Agua Amarga (Tupungato, Mendoza). Chungará, 40(2):145-160.

Ots, M. J. 2009. La población tardía del Valle de Uco y la dominación incaica en la frontera Suroriental del Qollasuyu. Y. Martini, G. Pérez Zavala y Y. Aguilar (comp.) Las Sociedades de los paisajes áridos y semiáridos del Centro Oeste argentino. Pp: 133-149. Universidad Nacional de Río Cuarto.

Oliszewski, N. 2009. El recurso maíz en sitios arqueológicos del noroeste argentino: el caso de la Quebrada de Los Corrales, El Infiernillo, Tucumán. Treballs d'Etnoarqueologia 7: 83-96.

Parisii, M. 1995. Aportes documentales y nuevas perspectivas sobre las organizaciones sociopolíticas prehispánicas del norte y Centro Oeste de Mendoza. Cuadernos del INAPL, 16: 121-152.

Parodi, L. 1959. Enciclopedia Argentina de Agricultura y Jardinería 1. ACME, Buenos Aires.

Parodi, L. 1966. La agricultura aborigen argentina. Cuadernos de América. Editorial Universitaria de Buenos Aires.

Pozner, R. 1998. Cucurbitaceae. Hunziker, H. (ed.) Flora Fanerogámica Argentina, 53: 1-58.

Prieto, M. del R. 2000 (1997-98). Formación y consolidación de una sociedad en un área marginal del Reino de Chile: la provincia de Cuyo en el siglo XVII. Anales de Arqueología y Etnología, 52-53.

Prieto O., C. 2005. "Alfarería Viluco en el Norte y Centro de la Provincia de Mendoza (Argentina). Nuevas perspectivas analíticas". Memoria para optar al título de Arqueóloga. Facultad de Ciencias Sociales, Departamento de Antropología, Universidad de Chile, Santiago de Chile. 214p.

Reitz, E. J., E. S. Wing. 1999. Zooarchaeology. Cambridge University Press. New York.

Roig, F.A., E. Martínez Carretero y E. Mendoza. s/f. Mapa de vegetación de la Provincia de Mendoza. Programa fitogeográfico argentino. IADIZA, CRICYT-Me. Inca ed., Mendoza.

Schiffer, M. B., J. M. Skibo. 1987. Theory and experiment in the study of technological change. Current Anthropology, 28 (5): 595-622.

Schiffer, M. B., J. M. Skibo, T. C. Boelke, M. A. Neupert y M. Aronson. 1994. New perspectives on experimental archaeology: surface treatments and thermal response of the clay cooking pot. American Antiquity, 59 (2): 197-217.

Singh, S. P., Gepts, P. y Debouck, D. G. 1991. Races of common bean (Phaseolus vulgaris, Fabaceae). Economic Botany, 45 (3): 379-396.

Skibo, J. M. 1992. Pottery function: a use-alteration perspective. Plenum Press, New York.

Skibo. J. M., M. B. Schiffer y K.C. Reid. 1989. Organictempered pottery: an experimental study. American Antiquity, 54 (1): 122-146.

Tani, M. 1995. Beyond the Identification of Formation Processes: Behavioral Inference Based on Traces Left by Cultural Formation Processes. Journal of Archaeological Method and Theory, 2 (3): 231-252.

Tapia, M. 1990. Cultivos andinos subexplotados y su aporte a la alimentación. Organización de las Naciones Unidas para la Agricultura y la Alimentación, FAO. Santiago de Chile.

Wandsnider, L. 1997. The Roasted and the Boiled: Food Composition and Heat Treatment with Special Emphasis on Pit-Hearth Cooking. Journal of Anthropological Archaeology, 16: 1-48.

Wilson, D. C. 1994. Secondary refuse aggregates. Journal of Archaeological Method and Theory, 1 (1): 41-68.

Yacobaccio, H., Madero, C. y M. Malmierca. 1998. Etnoarqueología de pastores surandinos. GZC. Grupo de Zooarqueología de Camélidos, Buenos Aires.

Zárate, M. A. 2002. Los ambientes del Tardiglacial y Holoceno en Mendoza. Gil, A. F. y G. A. Neme (eds.) Entre montañas y desiertos: arqueología del sur de Mendoza. Pp. 9-42. Sociedad Argentina de Antropología, Buenos Aires. 